\title{
Increasing adoption of precision agriculture via gamification: the farming simulator case
}

Book or Report Section

Other

Submitted version

Pavlenko, T., Paraforos, D. S., Fenrich, D., Braun, S., Murdoch, A., Tranter, R. ORCID: https://orcid.org/0000-00030702-6505, Gadanakis, Y. ORCID: https://orcid.org/00000001-7441-970X, Arnoult, M. and Engel, T. (2021) Increasing adoption of precision agriculture via gamification: the farming simulator case. In: Precision agriculture '21. Wageningen Academic Publishers, pp. 803-810. ISBN 9789086869169 doi: https://doi.org/10.3920/978-90-8686-916-9_96 Available at https://centaur.reading.ac.uk/99203/

It is advisable to refer to the publisher's version if you intend to cite from the work. See Guidance on citing.

Published version at: http://dx.doi.org/10.3920/978-90-8686-916-9_96

To link to this article DOI: http://dx.doi.org/10.3920/978-90-8686-916-9_96

Publisher: Wageningen Academic Publishers

All outputs in CentAUR are protected by Intellectual Property Rights law, including copyright law. Copyright and IPR is retained by the creators or other copyright holders. Terms and conditions for use of this material are defined in the End User Agreement. 


\section{www.reading.ac.uk/centaur}

\section{CentAUR}

Central Archive at the University of Reading

Reading's research outputs online 


\title{
Increasing adoption of precision agriculture via gamification: The Farming Simulator case
}

\author{
Pavlenko T. ${ }^{1}$, Paraforos D.S. ${ }^{2}$, Fenrich D. ${ }^{1}$, Braun S. ${ }^{1}$, Murdoch A. ${ }^{3}$, Tranter R. ${ }^{3}$, \\ Gadanakis Y. ${ }^{3}$, Arnoult M. ${ }^{3}$, Engel T. ${ }^{4}$ \\ ${ }^{1}$ Research Center for Bioeconomy, University of Hohenheim, Wollgrasweg 43, 70599 \\ Stuttgart, Germany \\ ${ }^{2}$ Institute of Agricultural Engineering, University of Hohenheim, Garbenstr. 9, 70599 \\ Stuttgart, Germany \\ ${ }^{3}$ School of Agriculture, Policy and Development, University of Reading, Whiteknights PO \\ Box 237, RG6 6EU Reading, UK \\ ${ }^{4}$ European Technology Innovation Center, John Deere GmbH \& Co. KG, Straßburger \\ Allee 3, 67657 Kaiserslautern, Germany \\ tetiana_pavlenko@uni-hohenheim.de
}

\begin{abstract}
Even though precision farming (PF) technologies offer apparent on-farm and off-farm benefits, their adoption rates depend on the type of technology. A lot of efforts are put towards increasing interest among farmers and other actors and motivating them to use PF techniques. Among others, gamification is a popular method that is being increasingly used not only in agriculture but in many other disciplines. This study describes the implementation of PF principles as an added application or downloadable content (DLC in the gaming community) in the Farming Simulator game. The developed DLC includes several new features: RTK base stations, soil texture classes, soil sampling, $\mathrm{pH}$ value, site-specific variable rate lime and nitrogen application, yield mapping and economic analysis.
\end{abstract}

Keywords: gamification, serious games, site-specific, soil sampling, variable rate

\section{Introduction}

The application of precision farming (PF) technologies gives access to a large amount of data that can be used for making informed decisions on farms (Paustian and Theuvsen 2017). These technologies have the potential to reduce costs, increase yields, and profit, as well as improve soils, water, and air quality (Kolady et al. 2020). There are different rates for the adoption of farm-level crop PF technologies. For some of them, the uptake is considered slow. For example, at the regional level, the adoption of variable-rate technologies (VRT) rarely exceeds 20\% (Lowenberg-DeBoer and Erickson 2019).

There are economic, sociological, environmental, and entrepreneurial aspects that influence the adoption of PF technologies (Pierpaoli et al. 2013). One of the ways to facilitate the adoption process is education and training among farmers and other interested stakeholders. In recent years, more attention has been given to convincing people to adopt technologies through serious games.

There are several studies on how serious games have been used in agriculture. The Horizon 2020 project "GATES" focused on the creation of a serious game-based training platform aimed to train actors of the agricultural value chain to apply smart farming technologies (GATES 2019). Kovács et al. (2017) have developed a farming simulator 
application with the main goal to introduce agriculture to students and young generations. Another study describes the gamification of the social agriculture application for increasing end-user engagement (Nuritha et al. 2017). A study from Markopoulos et al. (2020) introduced a virtual farming game promoting the use of effective best practices in rice production.

This work aimed to describe the development process of the PF DLC (downloadable content) as a part of the GIANTS Farming Simulator game (GIANTS Software GmbH, Zurich, Switzerland). The novelty of this work is that a game that is already being played by millions of users around the world, is used for the implementation of suitable aspects of PF. This gives a high probability that people involved in farming will become familiar with the benefits of PF and integrate these technologies into their farming business.

\section{Materials and methods}

\section{The Game}

The Farming Simulator is a simulation video game that was initially released in 2008 . The game is offered for 15 different platforms (PC, Xbox, etc.) while over 25 million copies have been sold (VentureBeat 2020). This game provides the player with the possibility to take the role of a farmer to do farming, grow crops, breed livestock, as well as sell all the assets that were created at the farm. The Farming Simulator is offered in 18 languages and is available in 165 countries (GIANTS Software 2020).

\section{$\underline{\text { Student workshops }}$}

Two student workshops were organised in the context of the project to identify which aspects of PF would be integrated into the game. The initial workshops were conducted with 25 postgraduate students at the two universities joining the project: The University of Reading, UK, and the University of Hohenheim, Germany. The objective of the first workshop was to present to the students the Farming Simulator game, to discuss with students the first ideas about the PF DLC, and to generate new ideas. Students with agricultural experience or involved in such studies were selected. A questionnaire was developed for the first workshop to collect initial ideas and feedback from the students. As the first workshops were organised before the development of the DLC, the second round of workshops was organised after the DLC release to gain feedback about the developed functionalities and how these could be improved. In total, 13 students participated. There were as well representatives from both universities and GIANTS. In advance, the questionnaire was sent to students to collect their feedback. During the workshop, after an introductory part, the students had time to play the DLC and practice the implemented features.

\section{Feedback from the first workshop with students}

Among the students who took part in the first round of workshops, 14 out of 25 students already worked or lived on a farm, or were likely to do so after completing their education. Whether or not the students worked or were planning to work on a farm later, 10 out of 25 were very likely to adopt precision agriculture on a farm, 13 were somewhat likely, and 2 were neutral. After having familiarised themselves with the concept of PF, around $55 \%$ of students were very likely to have it integrated into the Farming Simulator. The most essential features named by students to be added to the modification were variable rate $\mathrm{N}$ fertiliser application, variable-rate fungicide/insecticide application, variable rate 
seeding/planting, and the economic consequences of the above. Key takeaways from session 1 were that: a) most of the participants thought PF integration would increase realism and player engagement/awareness, b) however, the concept of PF and its implications might be too difficult for the average player to conceive and understand and consequently not be utilised in a way that would expand player knowledge of when, where, and why certain aspects would be used or needed.

Implemented PF principles

Based on the students' feedback and the consortium discussions, the following features were decided to be implemented:

- Automatic steering with RTK GNSS receiver.

- The introduction of soil heterogeneity based on different soil texture classes and different $\mathrm{pH}$ levels. The different soil texture classes correspond to a different level of yield potential.

- Soil sampling and soil properties based on laboratory analysis.

- Site-specific variable-rate lime spreading.

- Site-specific variable-rate $\mathrm{N}$ fertiliser spreading with two different options: (1) organic fertiliser (slurry manure), and (2) dry and liquid mineral $\mathrm{N}$ fertiliser.

- Yield logging on the combine harvester for grain crops and creation of yield maps.

- Economic analysis.

Mathematical calculations

The idea of the calculations was to find a compromise between simplicity that made playing the game fun and the more complex reality. Therefore, they were formulated based on the agronomic knowledge of the project partners and communication with other experts. The calculation of the effect of $\mathrm{N}$ fertilisation on crop yield was done based on the fertiliser impact on yield (FIY) as follows:

$$
(F I Y)=\frac{N \_ \text {organic_fertiliser }+N \_ \text {mineral_fertiliser }}{N_{\_} \text {demand }}
$$

if $F I Y \leq 1$ : Increasing yield until yield potential is reached (linear from 40 to $100 \%$ )

$$
\text { Yield }=\text { Yield potential } \times(0.4+0.6 \times F I Y)
$$

if $F I Y>1: 3 \%$ reduction per $10 \%$ over-fertilisation (only for cereals)

$$
\text { Yield }=\text { Yield potential } \times(1-(F I Y-1) \times 3)
$$

The economic analysis was designed to compare the single rate and variable rate fertilisation. This function is a simplification which only considers the variable costs of lime and $\mathrm{N}$ fertiliser because only these can be modified:

Gross margin in soil zone $\left(€ \cdot h a^{-1}\right)=$ Yield $\left(t \cdot h a^{-1}\right) \times$ price $\left(€ \cdot t^{-1}\right)-$ Constant_costs $\left(€ \cdot h a^{-1}\right)-\operatorname{Lime}\left(t \cdot h a^{-1}\right) \times \operatorname{lime} e_{-} \operatorname{costs}\left(€ \cdot t^{-1}\right)-$ $N_{-}$fertiliser $\left(\mathrm{kg} \cdot \mathrm{ha}^{-1}\right) \times N_{-} \operatorname{cost}\left(€ \cdot \mathrm{kg}^{-1}\right)$

where Constant_costs include costs like machinery, seed, pesticides, labour, etc. 
DLC development and implementation

The development process of the DLC was highly interactive with all parties that were part of the project and a handbook served as a basis for the DLC development. The features to be implemented were defined by partners based on their expertise and they were approved by GIANTS based on their practicability. The DLC was mainly developed in LUA, which is a multi-paradigm scripting language that allows having increased iterations in a small amount of time. This language is fundamental for the whole modding aspect that is possible with the game, as modders (i.e., players that can customise the game) can write their customisations in LUA. To configure the DLC, the extensible markup language (XML) was used, while the main game engine is developed in $\mathrm{C}++$.

\section{Results and Discussion}

\section{DLC release}

The PF DLC was developed and released on the 8th of December 2020. The DLC is free to use and can be downloaded and installed from the GIANTS website (GIANTS Software 2020). The new features of the DLC are described in the following sub-sections.

\section{$\underline{\text { RTK base stations }}$}

Two new buildings are available in the game shop: a small house and a garage. They both have a base station on the top that offers RTK correction to the GNSS receivers that were already available in the game before the development of the PF DLC. After placing the RTK base station on the farm, the operation can be accomplished more efficiently in terms of overlapping of the parallel infield passes. In comparison to the basic mode in which the automatic steering has $15 \%$ overlap, the automatic steering in the DLC has no overlap.

\section{Soil texture classes}

The DLC introduced four soil texture classes: loamy sand, sandy loam, loam, and silty clay. Each class has its characteristics that influence crop growth and, as a result, yield potential (Table 1). To get the maximum yield from a specific field, each soil texture class needs a special treatment to be applied. To identify which soil texture classes a player has and where they are located, soil sampling should be undertaken. The soil texture classes will become visualised on the map after the soil samples are taken and analysed.

$\mathrm{pH}$ value

Next to the soil texture class, a $\mathrm{pH}$ value is also determined and could be found on the $\mathrm{pH}$ value map. The DLC gives instructions to the players that depending on the soil texture class, the $\mathrm{pH}$ value should always be in the range that is defined for each soil texture class. The characteristics of management decisions are provided in Table 1.

Table 1. Connection between the $\mathrm{pH}$ of the four soil texture classes and yield potential.

\begin{tabular}{lcccc}
\hline & Loamy sand & Sandy loam & Loam & Silty clay \\
\hline $\mathrm{pH}$ & $5.0-6.5$ & $5.5-7.0$ & $6.0-7.5$ & $6.0-8.0$ \\
Yield potential $(\%)$ & 80 & 100 & 125 & 90 \\
\hline
\end{tabular}

Soil sampling 
For soil sampling (Error! Reference source not found.), two things are required: the Gator utility task vehicle (John Deere, Moline, IL, USA) and the ISARIA SCOUT (Fritzmeier Umwelttechnik GmbH \&
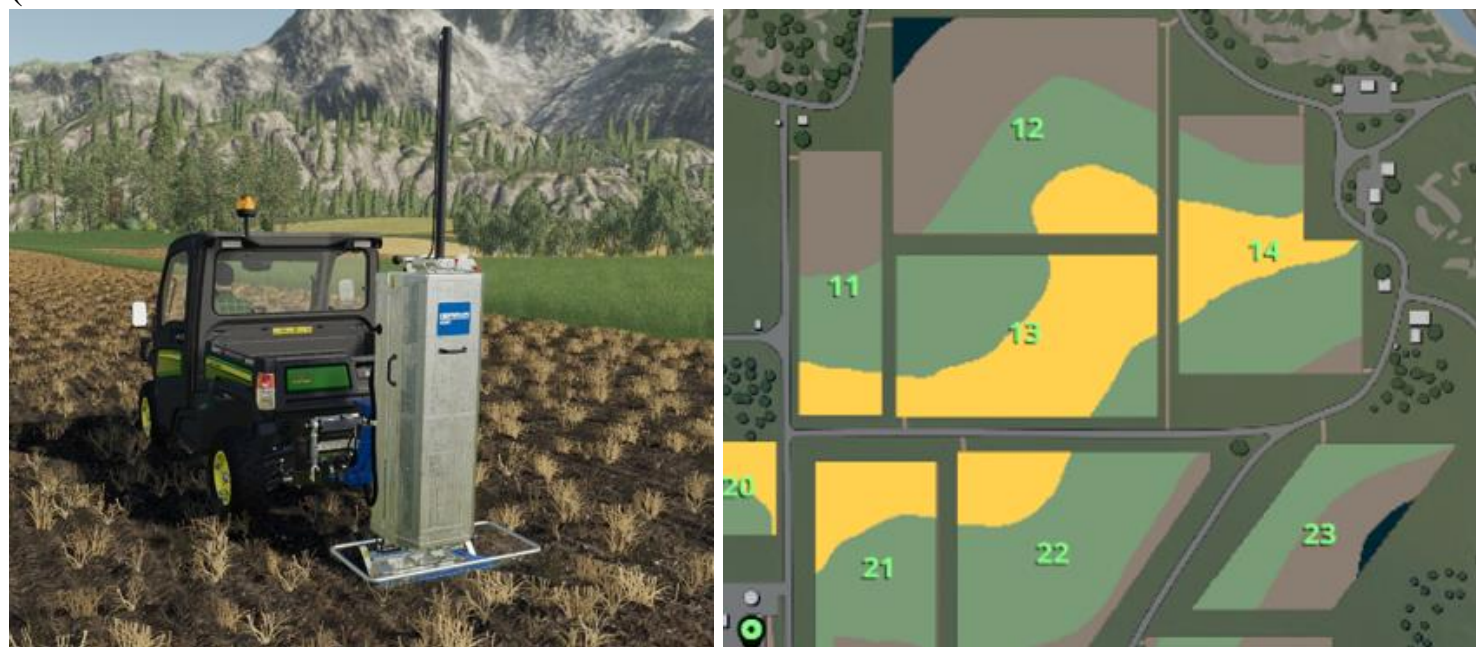

Loamy Sand

Sandy Loam

Loam

Silty Clay

Soil Sample Taken

Figure 1. (left) Soil sampling and (right) soil texture classes.

Co. KG, Großhelfendorf, Germany). With the sampler, the player can find out, which soil texture class the crops are growing on. The samples are collected in the vessels at the bottom of the unit. Every sample corresponds to a $32.5 \mathrm{~m}$ radius. After each soil sample is taken, a corresponding part of the field is coloured with dark red on the soil map. The best result is reached when the maximum amount of soil samples per field are collected so that the field is covered in dark red. The soil samples are then sent to the laboratory, where the analysis is performed. The price varies depending on the playing difficulty.

Site-specific variable lime application

The player can increase the $\mathrm{pH}$ value by liming the field (Figure 2). The DLC provides the lime application bar: the red marks show the current $\mathrm{pH}$ level (with an accuracy of three digits after the decimal point to make game playing more informative), while the flag shows the target $\mathrm{pH}$ value. As the player drives on the field, the application rate varies based on site-specific needs. In the game, it is recommended to apply lime every third harvest. If the $\mathrm{pH}$ value is not optimal, the yield decreases. The $\mathrm{pH}$ value decreases after every harvest, depending on the soil texture class. By default, based on the required 


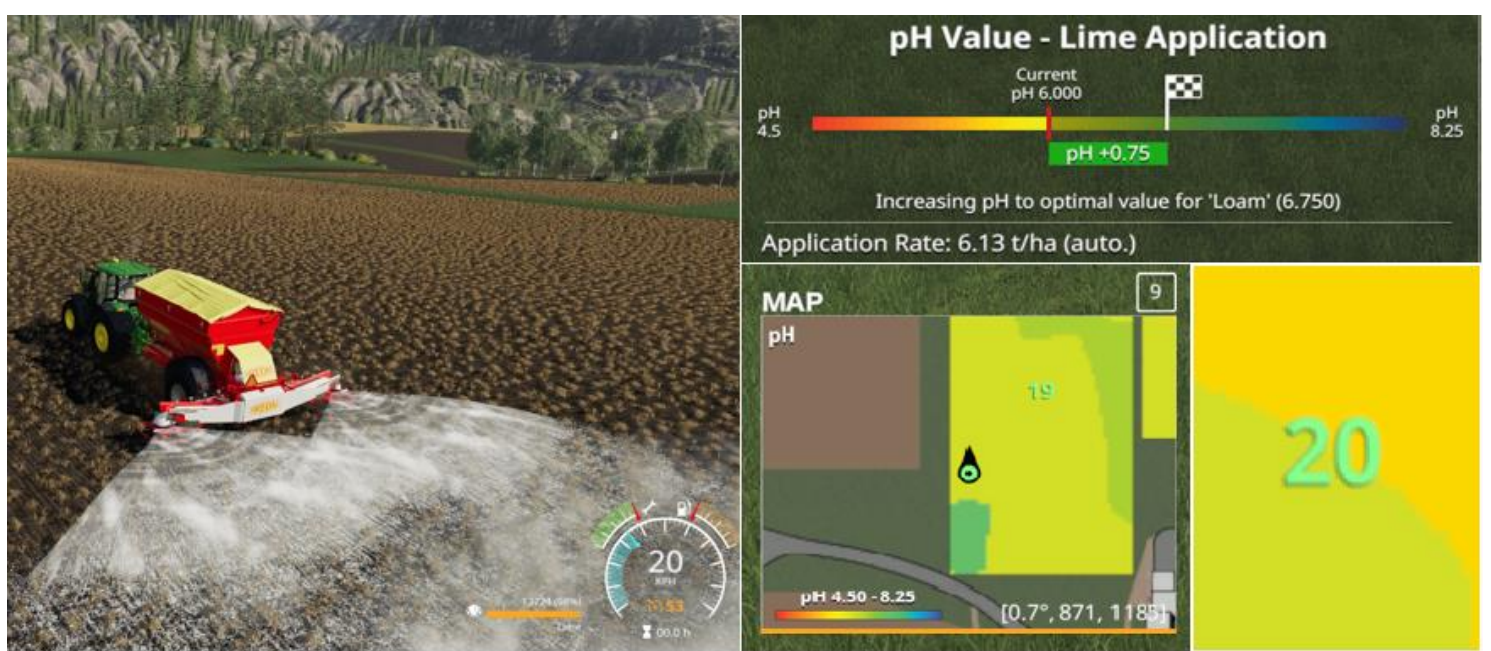

Figure 2. (left) Lime application and (right) current and targeted $\mathrm{pH}$ values.

Table 2. Connection between the soil texture classes and required lime spreading.

\begin{tabular}{lcccc}
\hline & Loamy sand & Sandy loam & Loam & Silty clay \\
\hline $\mathrm{pH}$ target value & 6.0 & 6.4 & 6.8 & 7.0 \\
$\begin{array}{l}\text { Amount of lime required } \\
\text { keep target level }\left(\mathrm{t} \mathrm{ha}^{-1}\right)\end{array}$ & 1.6 & 2.0 & 2.4 & 2.8 \\
\begin{tabular}{l} 
Reduction of $\mathrm{pH}$ per year \\
\hline
\end{tabular} & 0.075 & 0.095 & 0.115 & 0.135 \\
\hline
\end{tabular}

amount, the lime spreader automatically adjusts the application rate targeting the optimal $\mathrm{pH}$ level. Each soil texture class has a different optimal value. There is also an option to control the rate manually if the players wish so. The automatic mode chooses the amount of lime that needs to be spread based on the data in Table 2. An application of $0.7 \mathrm{tha}^{-1}$ of lime is required to increase the $\mathrm{pH}$ value by 0.1 . The reduction of $\mathrm{pH}$ per year in Table 2 was done based on the information provided by the Landwirtschaftskammer NordrheinWestfalen (LNW 2015).

Site-specific variable rate $\mathrm{N}$ application

An $\mathrm{N}$ map is implemented in the game (Figure 3). The player can see the current and target $\mathrm{N}$ level of a specific site on the field by driving to this field and looking at the "Field Info Display". The game offers the possibility to increase the N level using mineral or organic fertiliser. Depending on the crop that is planned to be sown, the player applies slurry or manure to the soil first. This helps to reduce the application rate and costs for the mineral $\mathrm{N}$ application later. Depending on the soil texture class, the application of slurry or manure increases its level by a fixed value (Table 3). Only one type of slurry manure is provided and it is assumed that the manure $\mathrm{N}$ content is homogeneous with a value of $4 \mathrm{~kg}$ of $\mathrm{N}$ per $\mathrm{m}^{3}$. After sowing the crop, the $\mathrm{N}$ level can be adjusted to the crop target value by applying mineral fertiliser. The player can choose a disc spreader or a sprayer. During liming or fertilising, the rising values could be seen live on the mini-map.

Table 3. Application of organic $\mathrm{N}$ fertilisation.

\begin{tabular}{lcccc}
\hline & Loamy sand & Sandy loam & Loam & Silty clay \\
\hline Suggested amount $\left(\mathrm{m}^{3} \mathrm{ha}^{-1}\right)$ & 10 & 15 & 20 & 15 \\
Amount of $\mathrm{N}\left(\mathrm{kg} \mathrm{ha}^{-1}\right)$ & 40 & 60 & 80 & 60 \\
\hline
\end{tabular}



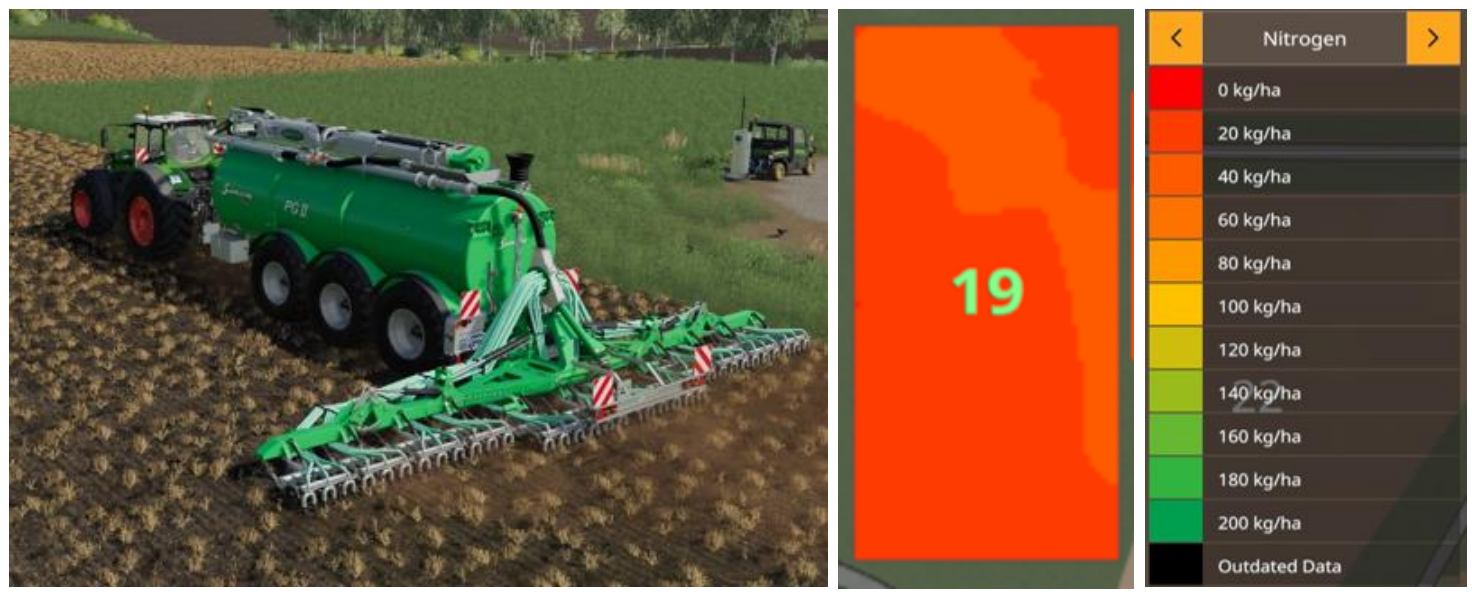

Figure 3. (left) $\mathrm{N}$ application of slurry and (right) the different $\mathrm{N}$ levels.
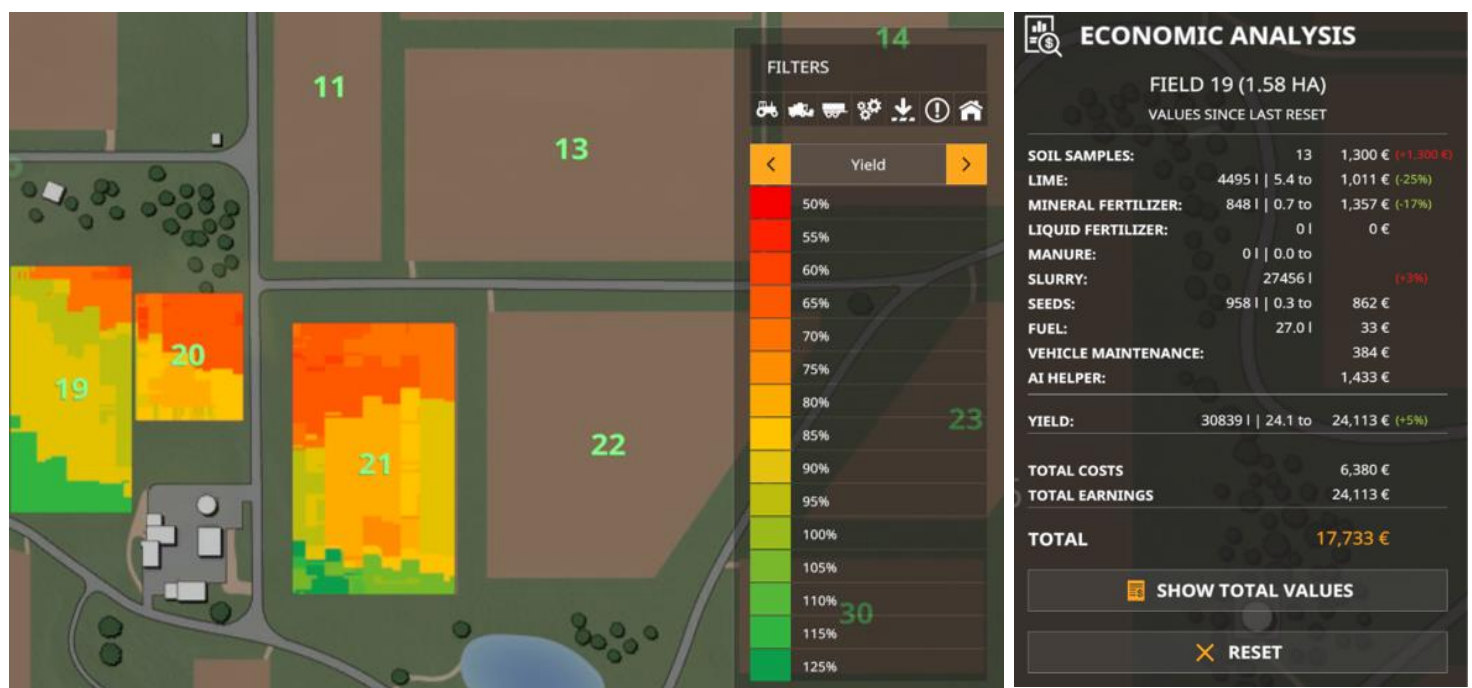

Figure 4. (left) Yield mapping and (right) economic analysis.

\section{Yield mapping}

The yield mapping offers the option to see the yield at specific spots in every field (Figure 4). Different yield potentials are prescribed for several crops. As a basis of $100 \%$ of the yield potential, the soil texture class 'sandy loam' was taken. A specific colour is assigned to each yield potential starting with red colour for low yields reaching green colour for high yields. Yield maps are also used to analyse the field afterward.

Economic analysis

Each field has information about its economic analysis. A window contains the costs, earnings, and total balance of the field. The player has the option to view the total values of the field or the statistics since the last time the reset button was pressed. The economic analysis provides a possibility to track the data over multiple harvests. Figure 4 shows the values for a specific field in the game. It provides costs for soil sampling, liming, fertilisation, seeds, fuels, vehicle maintenance, and labour. Besides, the total earning from the yield is provided. The player can see the total income with extracted costs.

$\underline{\text { Second workshop with students }}$ 
Students provided positive feedback about the DLC and they assessed it in the range between 'very easy' to 'neither easy nor difficult'. The release of the DLC was described as 'successful'. Students agreed or were more likely to agree, that PF and digitisation in agriculture can help to increase interest among younger people. Furthermore, they recommended decreasing the time for soil sampling as this was a highly repetitive task (even to sub-contract it). To make the DLC more realistic, it was suggested to have an option for variable-rate herbicide and fungicide application. A real-time in-cab view of the process monitoring in terms of variable rate application was also recommended.

\section{Conclusion}

The new DLC was a novel and innovative way to communicate the benefits of PF for reaching a wider audience of potentially interested stakeholders and to encourage the adoption of selected technologies. One of the challenges was to keep a balance between offering a game that is still fun and at the same time has functions that correspond to real PF principles and technologies. For the first version of the DLC, the mathematical calculations were simplified but an improvement is planned in the next steps of the DLC development. The project continues and future work includes site-specific sowing, varied slurry manure using state-of-the-art near-infrared sensor technology, variable-rate spraying, and crop rotation, which will be linked to residual $\mathrm{N}$ in the soil.

\section{Acknowledgements}

The work was performed through a project funded by the European Institute of Innovation \& Technology (EIT-Food) a body of the European Union, under the Horizon 2020, the EU Framework Program for Research and Innovation, project number 20224.

\section{References}

GATES. (2019). Gates | Smart Farming. https://www.gates-game.eu/en. (last accessed 22/02/21)

GIANTS Software. (2020). Precision Farming DLC | ModHub. https://farmingsimulator.com/mod.php?mod_id=188882. (last accessed 01/03/21)

Kolady, D. E., Van der Sluis, E., Uddin, M. M., and Deutz, A. P. (2020). Determinants of adoption and adoption intensity of precision agriculture technologies: evidence from South Dakota. Precision Agriculture. https://doi.org/10.1007/s11119-02009750-2

LNW. (2015). Kalkung Landwirtschaftskammer Nordrhein-Westfalen. https://www. landwirtschaftskammer.de/landwirtschaft/ackerbau/duengung/basisinfos/kalkungpdf.pdf. (last accessed 02/03/21)

Lowenberg-DeBoer, J., and Erickson, B. (2019). Setting the Record Straight on Precision Agriculture Adoption. Agronomy Journal 111, 1552-1569. https://doi.org/10.2134/ agronj2018.12.0779

Markopoulos, E., Chan, H. F. K., and Ming, L. L. (2020). Gamifying the Rice Industry: The "Riceville" Paradigm. In Advances in Intelligent Systems and Computing 973, 202-214. https://doi.org/10.1007/978-3-030-20476-1_21

Nuritha, I., Widartha, V. P., and Bukhori, S. (2017). Designing gamification on Social Agriculture (SociAg) application to increase end-user engagement. In proceedings 
of the 2017 4th International Conference on Computer Applications and Information Processing Technology (CAIPT), Kuta Bali, 1-5. https://doi.org/10.1109/CAIPT. 2017.8320713

Paustian, M., and Theuvsen, L. (2017). Adoption of precision agriculture technologies by German crop farmers. Precision Agriculture 18, 701-716. https://doi.org/10.1007/ s11119-016-9482-5

Pierpaoli, E., Carli, G., Pignatti, E., and Canavari, M. (2013). Drivers of Precision Agriculture Technologies Adoption: A Literature Review. Procedia Technology 8, 61-69. https://doi.org/10.1016/j.protcy.2013.11.010

Szilágyi, R., Kovács, T., Nagy, K., and Várallyai, L. (2017). Development of Farm simulation application, an example for gamification in higher education. Journal of Agricultural Informatics 8, 12-21. https://doi.org/10.17700/jai.2017.8.2.373

VentureBeat. (2020). Giants Software on the quiet, surprising success of Farming Simulator. https://venturebeat.com/2020/01/10/giants-software-on-the-quiet-surpris ing-success-of-farming-simulator. (last accessed 17/02/21) 